\title{
ANTIDIABETIC COMPOUNDS FROM MEDICINAL PLANTS USED IN THE INDIGENOUS SYSTEM OF MEDICINE ('DESHIYA CHIKITSA') IN SRI LANKA
}

\author{
BM \\ Malitha Aravinda Siriwardhene
}

\section{[15 JUN 2015 \\ MOD}

Thesis submitted to the University of Sri Jayewardenepura for the award of the Degree of Master of Philosophy in Pharmacology in August 2014 
We certified that the candidate has incorporated all corrections, amendments and additions recommended by the examiners.

Dr. A. K. E. Goonetilleke

Dr. G. A. Sirimal Premakumara

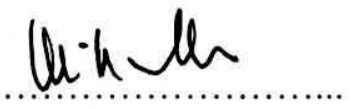

Date $15 / 06 / 2015$

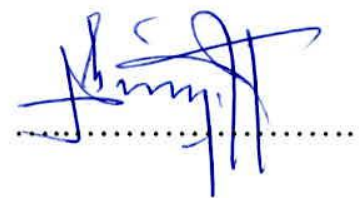

Date $.15 / 06 / 2015$ 


\section{DECLARATION}

"The work described in this thesis was carried out by me under the supervision of Dr.

A. K. E. Goonetilleke, Senior Lecturer, Department of Pharmacology, Faculty of Medical Sciences, University of Sri Jayewardenepura, Nugegoda and Dr. G. A. Sirimal Premakumara, Research fellow and former Director, Industrial Technology Institute, Colombo 7 and a report on this has not been submitted in whole or in part to any university or any other institution for anther Degree/Diploma".

$15106 / 2015$

Date

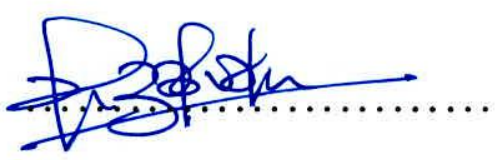

Signature 
"I certify that the above statement made by the candidate is true and that this thesis is suitable for submission to the University for the purpose of evaluation".

$15 \mid 06[2015$

Date

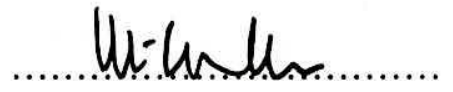

Dr. A. K. E. Goonetilleke

Senior Lecturer.

Dept. of Pharmacology,

Faculty of Medical Sciences,

University of Sri Jayewardenepura,

Nugegoda. 
"I certify that the above statement made by the candidate is true and that this thesis is suitable for submission to the University for the purpose of evaluation".

$15 \operatorname{lob} 2015$

Date

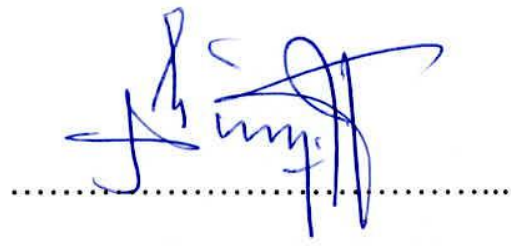

Dr. G. A. Sirimal Premakumara

(Research Fellow) 


\section{CONTENTS}

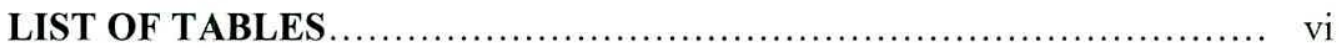

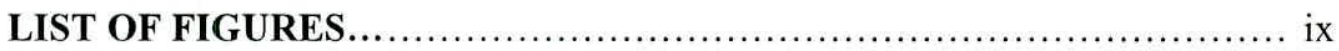

LIST OF ABBREVIATIONS .......................................... xii

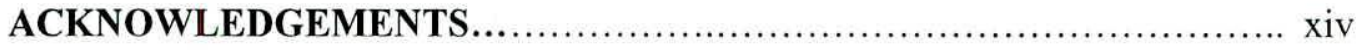

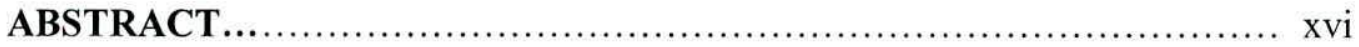

\subsection{INTRODUCTION}

1.1 Diabetes Mellitus and blood glucose homeostasis.............. 1

1.1.1 Diabetes Mellitus......................................... 1

1.1.2 The Classification of Diabetes Mellitus........................ 2

1.2 Prevalence of Diabetes Mellitus in Sri Lanka................... 3

1.3 Animal models in anti-diabetic evaluation..................... 4

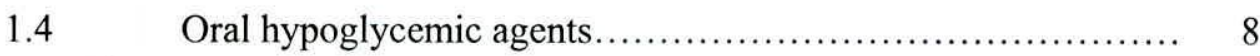

1.5 Phytomedicines in Diabetes Mellitus......................... 16

\subsection{LITERATURE REVIEWS}

2.1 Anti-diabetic ethno-medicine in Sri Lanka..................... 19

2.2 Costus speciosus Linn..................................... 20

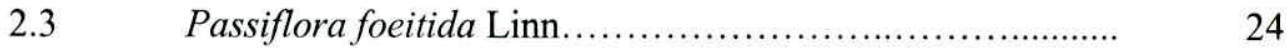

$2.4 \quad$ Ficus racemosa Linn........................................ 27

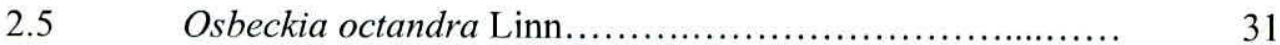


2.6 Averrhoa carambola Linn............................... 33

2.7 Aims and objectives of the thesis...................... 35

\subsection{MATERIALS AND METHODS}

$3.1 \quad$ Materials

3.1.1 Chemicals and reagents................................ 36

3.1 .2 Kits................................................. 37

3.1.3 Facilities............................................ 37

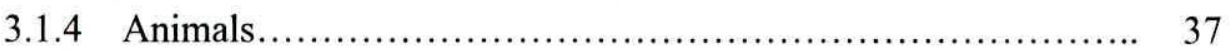

3.2 Methods

3.2.1 Survey on anti-diabetic medicinal plants used in Sri Lanka....... 38

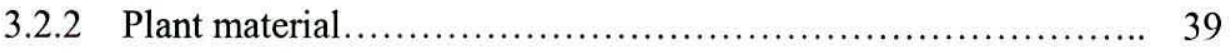

3.2.3 Extraction of plant material................................. 39

3.2.4 Bioactivity guided solvent partitioning of $80 \%$ methanol

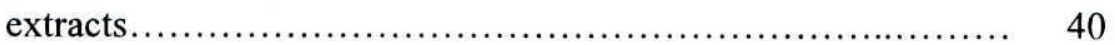

3.2.5 Preliminary phytochemical screening of $80 \%$ methanol

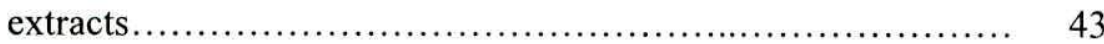

i. $\quad$ Test for alkaloids................................... 43

ii. $\quad$ Test for steroidal compounds......................... 44

iii. $\quad$ Test for phenolic compounds......................... 45

iv. Test for flavonoids................................ 45

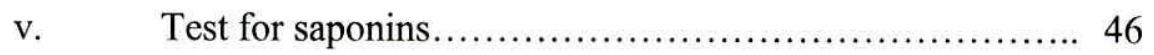


vi. $\quad$ Test for tannins.................................. 47

vii. Test for anthraquinones........................... 48

3.2.6 Quantitative determination of total phenols.................. 49

3.2.7 Spectrophotometric determination of total alkaloids............. 49

3.2.8 Spectrophotometric Determination of saponins ............... 50

3.2.9 Preliminary hypoglycemic activity of aqueous extracts........... 52

3.2.10 Evaluation of anti-hyperglycemic activity in glucose loaded

Normal Wistar rats.

3.2.11 In-vivo detail activity profile of the partitioned fractions

in rats.

i. Anti-hyperglycemic activity in normal Wistar rats............. 54

ii. The effect of pretreatment fractions on biochemical

parameters in normal and alloxan induced NIDDM

Wistar rats for 42 days.

iii. Collection of blood and determination of blood glucose levels 56

iv. Induction of non-insulin-dependent Diabetes

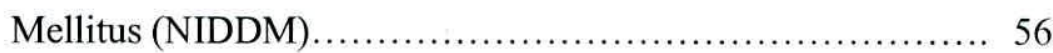

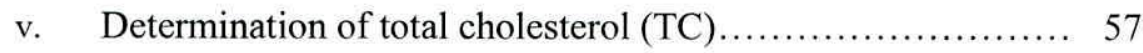

vi. Determination of serum high density lipoprotein

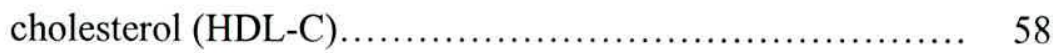

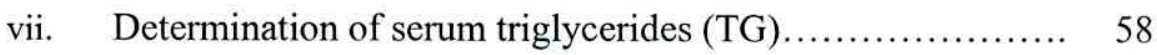

viii. Determination of low density lipoprotein cholesterol (LDL-C) 59 
ix. Determination of Anti-Atherogenic index (AAI) .............. 59

x. Determination of serum insulin ........................ 60

xi. Determination of glycosylated hemoglobin $\left(\mathrm{HbA}_{1 \mathrm{c}}\right) \ldots \ldots \ldots \ldots 61$

xii. Evaluation of serum creatinine and determination of renal function of the pretreatment active fractions on rat model.......63

3.2.12 Evaluation of in-vitro anti-oxidant activity..................... 63

3.2.13 Statistical analysis.......................................... 65

\subsection{RESULTS AND DISCUSSION}

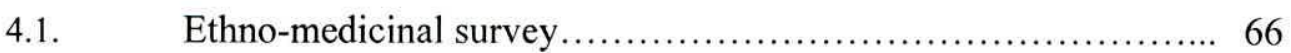

4.2. Extraction of plant material............................. 71

4.3. Dose response studies

4.3.1 Aqueous extracts.................................... 72

4.3.2 Standard anti-hyperglycemic agents.................... 76

4.4. The effect of hypoglycemic activities of aqueous, methanol and $n$-hexane extracts in normoglycemic rats................. 78

4.5. Bio-activity guided solvent partitioning ......................... 80

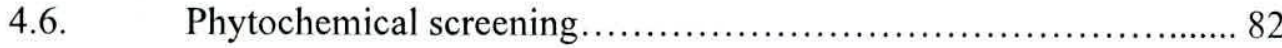

4.7. Total saponins, total alkaloids and total phenol contents........... 87

4.8. Evaluation of anti-diabetic activity of pretreatment partitioned fractions in rats for 42 days 
4.9. The evaluation of Oral Glucose Tolerance activity................92

4.10. The effect of biochemical parameters in correction of hyperglycemia......................................... 95

4.11. Determination of Anti-Atherogenic index (AAI) .............. 100

4.12. Evaluation of serum creatinine and assessment of dose dependent renal function............................. 101

4.13. Evaluation of in-vitro DPPH anti-oxidant activity.............. 104

4.14. Effect of food and water intake in rats for 42 days............. 106

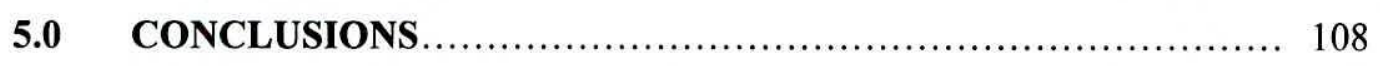

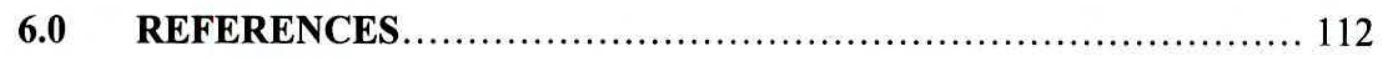

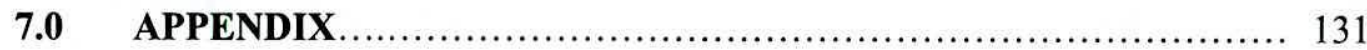




\section{LIST OF TABLES}

Table

Table 4.1: Results of ethno pharmacological survey of medicinal plants used in the treatment of Diabetes Mellitus in Sri Lanka....

Table 4.2: $\quad$ Percentage yield of water, ether and methanol

soluble plant extracts

Table 4.3: The dose response study of aqueous extracts

of selected medicinal plants.

Table 4.4: Comparative hypoglycemic activities of aqueous, methanol and $n$-hexane extracts of Costus speciosus, Passiflora foetida and Osbeckia octandra in rats

Table 4.5: Hypoglycemic activity of solvent partitioning fractions of Costus speciosus, Passiflora foetida and Osbeckia octandra in normal and alloxan induced NIDDM rats.

Table 4.6: Types of phytochemicals extracted by different solvents (Hughton and Raman 1998)

Table 4.7: Evaluation of the cumulative activity profile of the partitioned fractions of $80 \%$ methanol extracts 84

Table 4.8: Preliminary screening of the fractions of $80 \%$ methanol extract of Costus speciosus, Passiflora foetida and Osbeckia octandra leaves 86 
Table 4.9: Total phenol, total alkaloid and total saponin contents of Costus speciosus, Passiflora foetida and Osbeckia octandra......

Table 4.10: $\quad$ The effect of pretreatment fractions of $n$-hexane, ethyl acetate and $n$-butanol fractions of Costus speciosus, Passiflora foetida and Osbeckia octandra on normal and alloxan-induced NIDDM rats

Table 4.11: Effect of anti-hyperglycemic activity by OGTT of the fractions of Costus speciosus, Passiflora foetida and Osbeckia octandra on normal and alloxan-induced NIDDM rats

Table 4.12: Effect of pretreatment active fractions on lipid profile in alloxan induced NIDDM rats rats

Table 4.13: The effect of pretreatment of fractions of Costus speciosus, Passiflora foetida and Osbeckia octandra on biochemical parameters in alloxan-induced NIDDM Wistar rats for 42 days

Table 4.14: Effect of pretreatment fractions of Costus speciosus, Passiflora foetida and Osbeckia octandra on body weight and glycosylated hemoglobin in normal and alloxan-induced NIDDM rats for42 days 98 
Table 4.15: Effect of serum creatinine and estimation of GFR on pretreatment active fractions of Costus speciosus, Passiflora foetida and Osbechea octandra in normal and alloxan induced NIDDM Wistar

Table 4.16: The comparison of in-vitro DPPH Antioxidant activity of $80 \%$ methanol extract of plants with their active fractions when compared to ascorbic acid 104

Table 4.17: Effect of pretreatment fractions of Costus speciosus,

Passiflora foetida and Osbeckia octandra and glipizide on water intake of alloxan-induced NIDDM Wistar rats 106

Table 4.18: Effect of pretreatment fractions of Costus speciosus, Passiflora foetida and Osbeckia octandra glipizide on food intake of alloxan-induced induced NIDDM Wistar rats 107 


\section{LIST OF FIGURES}

Figures

Page

Figure 1.1: Chemical structure of sulphonylurea hypoglycemic

agents

Figure 1.2: Chemical structures of biguanide hypoglycemic agents

(a. Metformin and b. Phenformin) 10

Figure 1.3: Chemical structures of alpha-glucosidase enzyme inhibitor Acarbose

Figure 1.4: Chemical structures of Miglitol.

Figure 1.5: Chemical structure of Thiazolidinediones

(a. pioglitazone and b. rosiglitazone)

Figure 1.6: Chemical structures of Di-Peptidyl Peptidase-IV (DDP-IV)

inhibitors (gliptins: a. Vildagliptin, b. Saxagliptin

c. Sitagliptin and d. Alogliptin)

Figure 2.1 Leaves of Costus speciosus Linn 20

Figure 2.2 Leaves of Passiflora foetida Linn 24

Figure 2.3 Leaves of Ficus racemosa Linn 27

Figure 2.4 Leaves of Osbeckia octandra Linn.............................. 30

Figure 2.4 Leaves of Averrhoa carambola Linn ....................... 32

Figure 3.1: Preliminary extraction of plant materials for the investigation of anti-hyperglycemic activity. 40 
Figure 3.2: Scheme of representation of the solvent partitioning of $80 \%$ methanol extracts of Costus speciosus, Passiflora foetida and Osbechea octandra.

Figure 4.1: Frequency (as percentage informants) of Medicinal Plants used in the treatment of Diabetes Mellitus in Sri Lanka 67

Figure 4.2: Frequency of plant families in the treatment of Diabetes Mellitus in Sri Lanka. 70

Figure 4.3: Frequency of plant parts used in the treatment of Diabetes Mellitus in Sri Lanka. 70

Figure 4.4: The dose response activity of the two standard drugs (glipizide and metformin) on Wistar rats.

Figure 4.5: Comparison of percentage reduction in BGL $v s$ log dose for methanol extracts of plants and the two standard drugs glipizide and metformin on Wistar rats 77

Figure 4.6: Comparison of percentage reduction in BGL vs log dose of fractions of plants on Wistar rats 90

Figure 4.7: Percentage change in the body weight of the pretreatment of active fractions after 42 days when compared to the control group. 99 
Figure 4.8: Effects of fraction treatment on Anti-Atherogenic index (AAI) in normal and alloxan-diabetic rats. AAI were plotted before $\left(0^{\text {th }}\right.$ day $)$ and after daily oral treatment with vehicle (distilled water) and fractions for 42 days.................... 100

Figure 4.9: Relation of GFR with the weight $(\mathrm{kg}) /$ serum creatinine $(\mathrm{mmol} / \mathrm{L})$ in rats. 101

Figure 4.10: The effect of dose of active fractions vs GFR correlation of active fractions in normal and ARF induced rats.

Figure 4.11: Comparison of DPPH anti-oxidant effect of $80 \%$ Methanol extract of plants with their active fractions when compared to Ascorbic acid. 105 


\section{LIST OF ABBREVIATIONS}

80\%ME: $\quad 80 \%$ methanol extract

AAI: Anti-Atherogenic index

AE: $\quad$ Aqueous extract

AF: $\quad$ Remaining aqueous fraction

ALX: $\quad$ Alloxan monohydrate

BCG: $\quad$ Bromo cresol green solution

BGL: $\quad$ Blood glucose level

BF: $\quad n$-butanol fraction

CF: $\quad$ Chloroform fraction

CP: $\quad$ Corpulent rats

DM: Diabetes mellitus

DMSO: Dimethyl sulfoxide

DPPH: $\quad$ di (phenyl)-(2, 4, 6-trinitrophenyl) iminoazanium

EF: $\quad$ Ethyl acetate fraction

ELISA: Enzyme-linked immunosorbent assay

FBG: $\quad$ Fasting blood glucose concentration

GAE: Gallic acid equivalent

GK: Goto-Kakizaki rats

HbAic: $\quad$ Serum glycosylated hemoglobin

HDL-C: $\quad$ Serum high density lipoprotein cholesterol

HF: $\quad n$-hexane fraction

IDDM: Insulin-dependent diabetes mellitus

IDF: International Diabetes Federation 
KK: $\quad$ Mice of the KK strain develop diabetes of polygenic origin

LDL-C: $\quad$ Serum low density lipoprotein cholesterol

ME: $\quad$ Methanol extract

NIDDM: Non-insulin-dependent diabetes mellitus

OD 500 : Optical density at $500 \mathrm{~nm}$

PPAR: Peroxisome proliferator activated receptor

RC: $\quad$ Ratio of control

RT: $\quad$ Ratio of test

SEM: $\quad$ Standard error mean

STZ: $\quad$ Streptozotocin

TC: $\quad$ Serum total cholesterol

$\mathrm{TH}_{\mathrm{b}}$ Serum total hemoglobin fraction

TZDs: Thiazolidinedione

VLDL-C: Serum very low density lipoprotein cholesterol

WHO: World health organization

ZFR: Zucker fatty rats 


\section{ACKNOWLEDGEMENTS}

I would like to express my deepest gratitude to my advisors, Dr. A. K. E. Goonathilake, Department of Pharmacology, Faculty of Medical Sciences, University of Sri Jayewardenepura and Dr. G. A. Sirimal Premakumara (Doctorate Research Fellow), for his consistent supervision and dedication in guiding and following the work by devoting their golden time. And also Prof. A. M. Abeysekara, Department of Chemistry and Prof. U. G. Chandrika, Department of Biochemistry, for their constructive advice, encouragement, provision of chemicals, guidance and follow-up throughout this study. I would also like to acknowledge University of Sri Jayewardenepura and University Grant Commission for funding the project, Department of Chemistry and Department of Health Sciences for providing necessary chemicals and apparatus.

My gratitude also goes to Coordinator of the animal house for allowing me to use the animal house, and the staff of the animal house for their help in operating animal studies. I wish to thank all the staff members in Medical Research Institute, Ministry of Health, Sri Lanka, for providing me the necessary training program in animal handling.

I would also like to thank Prof. Ranil De Silva, Department of Anatomy and Prof. Kamani Samarasinghe, Dr. Inoka Uluwaduga and all the staff members of the Department of Health Sciences for their invaluable assistance during the study providing me advice. 
Finally yet importantly, I would like to express my deepest gratitude to my family, especially to my mother for her encouragement and support. 


\title{
ANTIDIABETIC COUMPOUNDS FROM MEDICINAL PLANTS \\ USED IN THE INDIGENOUS SYSTEM OF MEDICINE ('DESHIYA \\ CHIKITSA') IN SRI LANKA
}

\section{Malitha Aravinda Siriwardhene}

\begin{abstract}
The present study investigated the anti-diabetic effects of Costus speciosus, Passiflora foetida and Osbeckia octandra used in the treatment of DM in Sri Lanka. Eighty percent methanol extract (80ME) of C. speciosus, $P$. foetida and $O$. octandra leaf were evaluated for their hypoglycemic activity. Thereafter, the $80 \% \mathrm{ME}$ extracts of plants were partitioned with organic solvents $n$-hexane, chloroform, ethyl acetate and $n$-butanol to obtain $n$-hexane (HF), chloroform (CF), ethyl acetate (EF) and $n$-butanol (BF) soluble fractions. The dose response study of the plant extracts showed, at dose of $20 \mathrm{mg} / \mathrm{kg}$ was the most effective dose. Hence, the effects of partitioned fractions of $80 \mathrm{ME}$ on correction of hyperglycemia were tested at a dose of $20 \mathrm{mg} / \mathrm{kg}$ in three different rat models of diabetes viz., hypoglycemic, anti-hyperglycemic and ALX-diabetic (representing the type 2 diabetic model-NIDDM) using Swiss albino Wistar rats. The effects of extracts and fractions were compared with the effect of standard drugs metformin $(100 \mathrm{mg} / \mathrm{kg})$ and glipizide $(10 \mathrm{mg} / \mathrm{kg})$.
\end{abstract}

The fractions of EF and BF of $C$. speciosus and EF of both $P$. foetida and O. octandra produced significant $(\mathrm{p}<0.05)$ improvement in glucose tolerance activity compared to control rats. In the long-term study, once a day administration of $\mathrm{EF}$ and $\mathrm{BF}$ of both $P$. foetida and $O$. octandra $(20 \mathrm{mg} / \mathrm{kg})$ in both normal and ALX-diabetic rats produced significant $(\mathrm{p}<0.05)$ antidiabetic activity. However the effect produced by $P$. foetida and 
O. octandra fractions were lower than that of BF of $C$. speciosus. The study of serum biochemical parameters at a dose of $20 \mathrm{mg} / \mathrm{kg}$ showed that the $80 \% \mathrm{ME}$ fractions of $P$. foetida and $O$. octandra have potent hypolipidemic and anti-atherogenic activities. It also improved in liver enzyme activities on both normal and ALX diabetic rats. It was observed that both $C$. speciosus and $O$. octandra fractions increased serum insulin level and lowered lipid profile significantly $(\mathrm{p}<0.05)$ in both normal and ALX-diabetic rats. It finally concluded that the most active partitioned fractions of these plants are BF of $C$. speciosus, EFs of $P$. foetida and $O$. octandra. The DPPH scavenging in-vitro anti-oxidant activities of C. speciosus (BF), O.octandra (EF) and P. foetida (EF) fractions were compared against ascorbic acid showed similar anti-oxidant activities with that of ascorbic acid. The improved renal functions along with increased in Glomerular Filtration Rate (GFR), the effect of body weight and reduced serum creatinine indicates the renal safety in chronic use of these plant fractions in the treatment of DM. The phytochemical investigation revealed that the activity profile could be due to the synergistic interaction of small molecular weight compounds present in $80 \%$ methanol extracts which may be belongs to the plant secondary metabolites viz., phenolics, alkaloids or glycoside compounds. It also proven the ethno medicinal value of $C$. speciosus, O.octandra and $P$. foetida. Further detail characterization of chemical compounds which are responsible for hypoglycemic activity of these plants may provide a pathway to discover new chemical entities in the treatment of DM.

Key words: Costus speciosus, Passiflora foetida, Osbechea octandra, hypoglycemia and renal function 